\title{
DIRETRIZES CURRICULARES PARA A FORMAÇÃO DOCENTE: PERCEPÇÕES DE PROFESSORES FORMADORES
}

\author{
CURRICULAR GUIDELINES FOR TEACHER EDUCATION: VIEWS OF TEACHER \\ EDUCATORS
}

\section{DIRECTRICES CURRICULARES PARA LA FORMACIÓN DOCENTE: PERCEPCIONES DE PROFESORES FORMADORES}

Jane Mery Richter Voigt ${ }^{1}$

Marly Krüger de Pesce ${ }^{2}$

${ }^{1}$ Doutora em Educação pela PUC/SP. Docente do Mestrado em Educação da Universidade da Região de Joinville (UNIVILLE), Joinville, SC, Brasil.

${ }^{2}$ Doutora em Educação pela PUC/SP. Docente do Mestrado em Educação da Universidade da Região de Joinville (UNIVILLE), Joinville, SC, Brasil.

Resumo: O objetivo deste artigo é discutir como os professores que atuam em disciplinas relacionadas às práticas pedagógicas percebem os impactos das diretrizes curriculares para a formação inicial. Esta pesquisa, de abordagem qualitativa, obteve os dados por meio de entrevista com professores que atuam em cursos de licenciatura. A análise dos dados pautouse nas diretrizes nacionais (BRASIL, 2002; 2015) e em teóricos como Tardif (2011), Imbernón (2011) e Dourado (2015). Os resultados apontam que, para os formadores, diferentes saberes têm interfaces comuns e que a aproximação da universidade com a educação básica se mostra fundamental, pois a escola é reconhecida como um espaço de formação. Todavia há um silenciamento em relação a aspectos apontados nas diretrizes, como a formação do professor pesquisador, imprescindível para a atuação e formação docente, considerando as demandas e os desafios da educação.

Palavras-chave: Formação de Professores; Práticas Educativas; Diretrizes Curriculares.

Abstract: The aim of this article is to discuss how teacher educators who work with pedagogical subjects, understand the impacts of the guidelines for initial teacher education. Data for this research, which uses a qualitative approach, were collected through interviews with teacher educatorsworking with degreecourses. ThedataanalysistookintoaccounttheNational Guidelines (Brasil, 2002; 2015); and authors such as Tardif (2011), Imbernón (2011) and Dourado (2015). The results indicate that for the educators, different types of knowledge have common interfaces, and the relationship between the university and basic education is fundamental, as the school 
is recognized as a space of training. However, there was a silence in relation to aspects pointed out in the Guidelines, such as the education of the teacher as a researcher, which is essential for teaching performance and training, considering the demands and challenges of education.

Keywords: Teacher training education; Educational practices; Curricular Guidelines.

Resumen: El objetivo de este artículo es discutir como los profesores que actúan en materias relacionadas a las prácticas pedagógicas, entienden los impactos de las directrices curriculares para la formación inicial de maestros. Esta investigación, de abordaje cualitativa obtuvo los datos por medio de entrevistas con profesores que actúan en cursos de Licenciatura. El análisis de los datos se basó en las directrices nacionales (Brazil, 2002; 2015) y en teóricos como Tardif (2011), Imbernón (2011) y Dourado (2015). Los resultados apuntan que, para los profesores, diferentes saberes tienen interfaces comunes y que la aproximación de la universidad con la educación básica es fundamental, porque la escuela es reconocida como un espacio de formación. No obstante, hay un silenciamiento en relación a los aspectos resaltados en las directrices como la formación del profesor investigador, imprescindible para la actuación y formación docente, considerando las demandas y los desafíos de la educación.

Palabras clave: Formación de profesor; Prácticas educativas; Directrices curriculares.

\section{INTRODUÇÃO}

Em decorrência de mudanças nas diretrizes nacionais para a formação de professores nas últimas décadas, os cursos de licenciatura vêm sofrendo alterações na organização de seus projetos político-pedagógicos, o que acarretou mudanças no perfil do egresso e, consequentemente, do professor da Educação Básica.

Em 2002, o Conselho Nacional de Educação emitiu Diretrizes Curriculares Nacionais para a Formação de Professores da Educação Básica (Brasil, 2002), estabelecendo que o formando deve ser capaz de relacionar teoria e prática e que as questões pedagógicas precisam permear todo o curso e não apenas concentrar-se nos anos finais. Nessa perspectiva, as matrizes curriculares passaram a contemplar com maior intensidade as disciplinas pedagógicas, devendo levar a uma maior integração destas com as disciplinas específicas dos cursos.

Para compreender as percepções dos professores formadores em relação às mudanças propostas, foi desenvolvida uma pesquisa em uma universidade comunitária do sul do Brasil que atendeu às diretrizes nos projetos pedagógicos dos cursos de licenciatura. A questão que norteou a pesquisa foi: Em que medida as alterações propostas nos projetos pedagógicos, de acordo com as Diretrizes Curriculares Nacionais para a Formação de Professores da Educação Básica (Brasil, 2002), atendem à formação necessária para a atividade docente?

Em 2009 a instituição pesquisada delineou um perfil profissiográfico comum a todos os cursos oferecidos por ela no que se refere à formação para a docência. Tal perfil foi utilizado em todos os Projetos Pedagógicos dos Cursos de Licenciatura (PPCs), assumindo que: a docência é a base na formação profissional em educação; a formação teórica nos conteúdos específicos e nos conteúdos pedagógicos deve constituir a matriz do curso em toda a sua dimensão; as experiências curriculares devem permitir contato dos futuros profissionais com a realidade da 
docência desde o início do curso; a reflexão sobre questões mais amplas do papel social e político da docência e sobre a formação para o magistério precisa estar presente.

Uma das formas idealizadas por essa universidade para propiciar esses princípios foi oferecer as disciplinas de formação pedagógica com matrícula de estudantes oriundos dos vários cursos de licenciatura em andamento. Dessa forma, eles têm a oportunidade de, ao cursar disciplinas de formação pedagógica com colegas de outras áreas do conhecimento, realizar trabalhos interdisciplinares e dialogar com outros saberes para além da especificidade de sua área de formação.

Diante da experiência apresentada, faz-se importante ressaltar que as concepções teóricometodológicas que embasam os projetos pedagógicos de cursos de licenciatura, assim como a prática dos professores formadores, são elementos que participam da constituição identitária do futuro professor. Para Marcelo (2009, p. 9), a formação docente está relacionada aos "processos usados pelos professores nas suas aprendizagens, processos esses que desenvolvem e melhoram o seu repertório de competências".

Assim, considerando que a formação inicial representa o momento de aprender e vivenciar questões preliminares do exercício profissional (NÓVOA, 1992), o foco deste artigo é refletir sobre os resultados de um estudo que investigou aspectos relacionados a como os professores formadores que atuam em disciplinas relacionadas às práticas pedagógicas percebem os impactos das diretrizes curriculares, por meio das alterações nos projetos pedagógicos para a formação inicial.

\section{Percurso metodológico}

A pesquisa a qual se refere o presente artigo é de abordagem qualitativa, uma vez que investiga opiniões, percepções, representações, sentimentos, centrando-se na visão do sujeito e no objetivo do que se está investigando (GATTI; ANDRÉ, 2010). Tal abordagem se centra na perspectiva dos sujeitos ao investigar as suas percepções sobre as mudanças provocadas nos cursos de formação inicial de professores decorrentes das políticas públicas de formação.

$\mathrm{Na}$ análise de uma pesquisa dessa natureza, estará presente o quadro de referência do pesquisador, seus valores, sua visão de mundo, que são marcas da subjetividade e que caracteriza a dimensão qualitativa (ANDRÉ, 2007).

A pesquisa foi realizada com professores formadores que lecionam em uma universidade comunitária da região sul do Brasil, a qual oferece cursos de licenciatura na modalidade presencial há cerca de 50 anos. Os cursos oferecidos pela instituição são: Artes Visuais, Ciências Biológicas, Educação Física, História, Letras e Pedagogia. No período letivo de realização da pesquisa, 18 professores lecionavam nas diversas disciplinas pedagógicas, dos quais seis se dispuseram a participar da pesquisa.

Para coletar os dados, aplicou-se uma entrevista semiestruturada, cujo roteiro de questões compreendeu aspectos relacionados à contribuição do estudo das disciplinas pedagógicas para a formação do professor ante as diretrizes curriculares e os projetos pedagógicos dos cursos de licenciatura e os desafios para o professor formador diante das políticas nacionais e 
institucionais de formação. As questões propostas permitiram discutir sobre as percepções dos professores formadores em relação aos impactos da implementação das diretrizes curriculares nos cursos de licenciatura.

Optou-se pela entrevista semiestruturada, porque ela valoriza a presença do investigador e favorece as possibilidades de que o sujeito pesquisado tenha liberdade e espontaneidade, enriquecendo o estudo (TRIVIÑOS, 1987).

Podemos entender por entrevista semi-estruturada, em geral, aquela que parte de certos questionamentos
básicos, apoiados em teorias e hipóteses, que interessam à pesquisa, e que, em seguida, oferecem
amplo campo de interrogativas, fruto de novas hipóteses que vão surgindo à medida que se recebem
as respostas do informante. Dessa maneira, o informante, seguindo espontaneamente a linha
do seu pensamento e de suas experiências dentro do foco principal colocado pelo investigador,
começa a participar da elaboração do conteúdo da pesquisa. (TRIVIÑOS, 1987, p. 146).

Além disso, na entrevista semiestruturada as perguntas são normalmente preestabelecidas, mas o pesquisador está livre para ir além das respostas, buscar tanto esclarecimento quanto a elaboração das respostas dadas, estabelecendo um diálogo com o entrevistado, o que pode gerar "compreensões ricas das biografias, experiências, opiniões, valores, aspirações, atitudes e sentimentos das pessoas" (MAY, 2004, p. 145).

As entrevistas foram gravadas e, posteriormente, transcritas. Os dados foram organizados de modo a identificar, de acordo com Lüdke e André (1986), padrões e tendências relevantes nas respostas dos sujeitos. Dessa forma, a discussão dos tópicos será apresentada com base no referencial teórico da pesquisa e permeada pelas falas dos entrevistados.

\section{Formação Inicial: Saberes Necessários Para A Docência}

O ato de ensinar se constitui na relação dos sujeitos envolvidos com a aquisição do conhecimento e é, segundo Tardif e Lessard (2005, p. 8), “[...] uma forma particular de trabalho sobre o humano, ou seja, uma atividade em que o trabalhador se dedica ao seu 'objeto' de trabalho, que é justamente outro ser humano, no modo fundamental da interação humana". Nesse sentido, o exercício da docência leva à transformação dos sujeitos participantes do processo de ensino-aprendizagem.

Ao se considerar que a tarefa do professor é ensinar, deve-se levar em conta o conceito do que é ensinar. Para exercer com propriedade sua tarefa, o professor tem de conhecer muito bem o conteúdo da disciplina que leciona, além de dominar os saberes do campo da educação. Esses saberes habilitam-no a desenvolver sua atividade, objetivando a aprendizagem do aluno e não simplesmente a transmissão do conteúdo. Ou seja, ensinar é uma ação cognoscível e deliberada que o professor deve ter para mobilizar e mediar a aprendizagem de um conteúdo do qual o aluno deve apropriar-se, sendo tal ação específica desse profissional.

Tardif (2011) destaca que o professor não trabalha com objetos, mas com pessoas, por isso o seu trabalho é de cunho social; ensinar é agir com outros seres humanos, numa relação 
em que se conhecem os papéis específicos de cada um: o de ensinar e o de aprender. A tarefa de ensinar requer saberes específicos da docência, sendo eles: os saberes da formação profissional, os saberes disciplinares, os saberes curriculares e os saberes experienciais. Na fala do Professor A, observa-se que a proposta pedagógica dos cursos favorece a articulação dos diferentes saberes. Ele afirma que o diálogo deve acontecer entre as disciplinas dos cursos de formação e as pedagógicas, considerando como pano de fundo a docência:

E os estudantes, na medida em que isso acontece, percebem que os saberes têm interfaces. Então, na verdade, partese de uma ação de disciplinas que a princípio são isoladas, mas que se buscou uma forma institucional de fazer com que essas disciplinas se aproximem e tenham um diálogo. Que os alunos de diferentes cursos também se aproximem e construam um diálogo tendo como base até a própria questão da identidade do professor, que é o que eles serão.

A identidade apontada pelo Professor A é constituída com os saberes da formação profissional, os quais são provenientes do conhecimento a respeito das ciências da educação e de métodos e técnicas pedagógicas estudados eapreendidos em instituições de formação inicial. Os disciplinares consistem no domínio do conhecimento específico das diversas áreas a serem ensinadas. Os saberes curriculares correspondem aos discursos, aos objetivos, aos conteúdos e aos métodos (programas escolares) trabalhados nas instituições de ensino. A tarefa diária de ensinar e o conhecimento do professor sobre o meio em que está inserido produzem saberes experienciais ou saberes da prática docente; estes brotam da experiência e por ela são validados.

Os saberes não são lineares nem hierárquicos, e sim elementos constitutivos da prática docente dos professores.

Essa dimensão da profissão docente lhes confere o status de prática erudita que se articula, simultaneamente,
com diferentes saberes: os saberes sociais, transformados em saberes escolares, através dos saberes disciplinares
e dos saberes curriculares, os saberes oriundos das ciências da educação, os saberes pedagógicos e os
saberes experienciais. Em suma o professor ideal é alguém que deve conhecer sua matéria, sua disciplina,
e seu programa, além de possuir certos conhecimentos relativos às ciências da educação e a pedagogia e
desenvolver um saber prático baseado em sua experiência no cotidiano com os alunos. (TARDIF, 2011, p. 39).

Levando em conta que há saberes necessários para a atuação docente e um dos espaços no qual se constituem esses saberes são os cursos de licenciatura, é necessário destacar que a formação inicial deve, entre outros aspectos, fornecer bases para a construção de um conhecimento pedagógico especializado, oferecer conhecimentos que sejam válidos e que gerem uma atitude interativa e dialética, o que parece ser evidenciado pelo Professor $A$.

Essa formação precisa ainda apresentar um currículo formativo que provoque experiências interdisciplinares que deem condições ao futuro docente para integrar os conhecimentos didáticos aos conhecimentos psicopedagógicos. Porém, em muitos casos, os cursos de formação inicial de professores parecem não dar conta do princípio dialético constitutivo da docência (IMBERNÓN, 2011).

Mesmo sendo um desafio, ao proporcionar experiências interdisciplinares, a vivência do Professor A revela:

Então eu acho essa experiência bem importante e acho que trazuma contribuição importante para a emancipação do aluno. Confrontar-se com outras formas de pensar, com outras áreas de conhecimento, com colegas que estão sentados dentro da sala de aula e que vêm de realidades diferentes e que vão futuramente trabalhar com áreas de conhecimento diferentes. 
Formosinho (2009, p. 107) entende que "a assunção de uma cultura profissional de formação pressupõe considerar os estudantes, para além de alunos de disciplinas curriculares, como futuros ou potenciais professores, o que implica propor-lhes diferentes estratégias de aprendizagem". Para a Professora B, na educação não há fronteira:

[...] pois o objeto de estudo da Pedagogia é a educação e o homem - neste caso, o homem, a mulher, a criança, o adolescente - que é o sujeito da Educação. Ali não tem fronteira, então automaticamente a Pedagogia, como Ciência da Educação, já é interdisciplinar, pois o núcleo da discussão é o sujeito da educação e a própria educação. E aí nós vamos discutir uma questão importante que é a de como se faz a educação desse sujeito. É aí que está a Pedagogia para falar dos processos de condução, mas para ter esses processos obrigatoriamente você tem que ter os fundamentos.

A opção pelo conceito de interdisciplinaridade na formação de professores como atitude para a construção do conhecimento vem ao encontro de uma necessidade da escola de Educação Básica, como afiança a Professora C: "De certa forma, parece que é isso que a escola está pedindo hoje: um profissional que não atue aqui e ali, mas que tenha um olhar mais amplo". Para ampliar essa discussão, considera-se relevante abordar, com base em Fazenda (2009), duas ordenações no tocante à formação interdisciplinar de professores: a ordenação científica e a ordenação social.

A ordenação científica representa a organização dos saberes do conhecimento científico da formação de professores. Nesse sentido, as disciplinas didático-pedagógicas devem contemplar os fundamentos teóricos e metodológicos próprios de sua cientificidade, que adquire status interdisciplinar quando o professor revê as suas práticas.

A ordenação social implica considerar os saberes científicos interdisciplinares numa perspectiva de demandas sociais, ou seja, a formação docente deve proporcionar a superação da dicotomia entre teoria e prática, considerando as condições sociais e históricas das práticas dos professores, as quais muitas vezes são um obstáculo que precisa ser superado, pois, conforme relato da Professora C, "primeiro porque existe uma lógica do próprio professor em pensar a sua disciplina, o seu encaminhamento... Existe um perfil".

Tardif $(2011$, p. 36) define o saber docente como "um saber plural, formado pelo amálgama, mais ou menos coerente, de saberes oriundos da formação profissional e de saberes disciplinares, curriculares e experienciais". Ele afirma que o professor, em sua prática cotidiana, se apoia em sua experiência e faz uso de seus conhecimentos pessoais na construção de um saber-fazer personalizado, que dê conta de suas múltiplas atribuições.

O autor chama a atenção para a natureza social do saber profissional, considerando que:

[...] os diversos saberes dos professores estão longe de serem todos produzidos diretamente por eles, e muitos deles são de certo modo "exteriores" ao ofício de ensinar, pois provém de lugares sociais anteriores à carreira propriamente dita, ou estão situados fora do trabalho cotidiano. (TARDIF, 2011, p. 64).

Com base nas falas dos sujeitos da pesquisa e na literatura, entende-se que as atividades interdisciplinares representam um avanço na qualificação do trabalho docente, por se constituírem em oportunidades de experienciar o convívio com diferentes perspectivas técnico-científicas e diferentes conjuntos de valores; ainda que haja dificuldades na compreensão do conceito de 
interdisciplinaridade e de sua efetivação no cotidiano dos cursos de formação de professores. As alterações nos projetos pedagógicos dos cursos de licenciatura, com base na análise dos dados, favoreceram o diálogo entre os saberes e as diferentes áreas do conhecimento, o que era uma das prerrogativas das diretrizes de 2002.

\section{Políticas Para A Formação De Professores}

As discussões sobre a formação de professores na década de 1980 estavam pautadas na ideia de que o modelo da racionalidade técnica deveria ser superado. Esse modelo pressupõe que a atuação docente é regulada por um sistema lógico e infalível de procedimentos, constituído a partir de um conjunto de premissas (CONTRERAS, 2002), o qual não respondia às exigências e aos desafios da educação na sociedade contemporânea.

Nessa perspectiva, os cursos de formação de professores precisavam preparar profissionais da educação que, além de conhecer o conteúdo da disciplina que lecionavam, dominassem também os saberes do campo da educação. Essas exigências os habilitariam a desenvolver sua atividade, objetivando a aprendizagem do aluno e não simplesmente a transmissão do conteúdo, refletir sobre a prática e significá-la. Entendia-se que o conceito de professor reflexivo poderia ser mais adequado.

No processo de reflexão-na-ação o aluno-mestre não pode limitar-se a aplicar técnicas aprendidas ou os métodos de investigação consagrados, devendo também aprender a construir e a comparar novas estratégias de ação, novas fórmulas de pesquisa, novas teorias e categorias de compreensão, novos modos de enfrentar os problemas. Em conclusão, o profissional reflexivo constrói de forma idiossincrática o seu próprio conhecimento profissional, o qual incorpora e transcende o conhecimento emergente da racionalidade técnica. (PÉREZ GÓMEZ, 1995, p. 110).

Partindo dessas premissas, a preocupação com a qualidade da formação inicial nesse período se concretizou com a proposição de Diretrizes Curriculares Nacionais para a Formação de Professores da Educação Básica (BRASIL, 2002). As diretrizes propuseram mudanças em relação à natureza dos componentes curriculares dos cursos de licenciatura. As matrizes curriculares dos cursos passaram a contemplar com maior intensidade as disciplinas pedagógicas e houve maior integração destas com as disciplinas específicas dos cursos. Dentre outras mudanças, elas previram que a formação para a prática profissional deveria estar presente desde o início do curso, o que acarretou uma nova redistribuição da carga horária dos componentes curriculares. Além disso, não somente as disciplinas pedagógicas, como também os demais componentes curriculares, precisariam ter sua dimensão prática. Portanto, o estudante de licenciatura entraria em contato com as práticas ao longo do seu processo de formação, o que Ihe oferecia, de acordo com Gatti (2009), melhores condições em participar de experiências mais contextualizadas e significativas para a construção da sua prática pedagógica.

Nessa direção, os professores da instituição pesquisada percebem a formação inicial para além da universidade, buscando parcerias com os professores nas escolas de educação básica, 
[...] a escola também é um espaço múltiplo. A escola é um espaço que ao longo do tempo também tem tentado romper os seus muros. A escola tem que ser percebida cada vez mais como parte de um segmento da sociedade, e que os muros são, por mais que físicos, mas eles podem ser rompidos e devem ser rompidos.

Outra forma de aproximação entre a instituição formadora e a escola de Educação Básica foi a criação do Programa Institucional de Bolsas de Iniciação à Docência (PIBID), do qual a universidade desta pesquisa participa. O PIBID, instituído pela Portaria Normativa n. ${ }^{\circ} 16$, de 23 de dezembro de 2009 (CAPES, 2009), normatiza a concessão de bolsas para alunos de cursos presenciais de licenciatura que se dedicam ao estágio nas escolas públicas, para professores formadores e para professores da escola pública. O Programa tem entre seus principais objetivos:

f) estimular a integração da Educação Superior com a Educação Básica no Ensino Fundamental e Médio, de modo a estabelecer projetos de cooperação que elevem a qualidade do ensino nas escolas da rede pública; g) fomentar experiências metodológicas e práticas docentes de caráter inovador, que utilizem recursos de tecnologia da informação e da comunicação, e que se orientem para a superação de problemas identificados no processo ensino-aprendizagem; h) valorizar o espaço da escola pública como campo de experiência para a construção do conhecimento na formação de professores para a educação básica (CAPES, 2009, p. 1).

A experiência dos licenciandos em projetos desenvolvidos pelo Programa tem favorecido a relação entre teoria e prática e transformado a realidade escolar, o que é apontado pela Professora D: "Algumas diretoras de escolas, até por conta do PIBID, nós vamos à escola, e elas dizem que os alunos de nossa universidade, de uns cinco anos para cá, vêm fazendo a diferença no olhar de proposta para a escola".

Por meio da aproximação com a escola de Educação Básica, a construção dos saberes para a docência não se dá exclusivamente no âmbito da universidade, mas também na inserção no campo de trabalho. A aproximação com a Educação Básica atende a um dos princípios das novas diretrizes para a formação inicial, quando defendem a necessidade de "articulação entre a teoria e a prática no processo de formação docente, fundada no domínio dos conhecimentos científicos e didáticos, contemplando a indissociabilidade entre ensino, pesquisa e extensão" (BRASIL, 2015, p. 5).

Pesquisadoras como Romanowski e Martins (2010), ao analisarem trabalhos sobre a situação das licenciaturas, ratificam que as diretrizes propostas em 2002 para os cursos de licenciatura desencadearam, tanto em instituições públicas como privadas, processos de reformulação dos cursos, porém elas continuam centradas na formação técnica, sem superação da fragmentação da teoria e da prática, do conteúdo e do método. Como essa racionalidade se apresenta configurada por uma nova epistemologia da prática, que tem a reflexão e a investigação como motriz da aprendizagem do ofício, gera um embate quanto à concepção de formação docente. As autoras exemplificam dizendo que há diferentes conflitos como nos cursos centrados nos conteúdos específicos, nos que procuram imprimir à docência uma identidade própria, nos 
que confirmam a formação centrada nas competências.

Além das dificuldades apontadas, há críticas em relação ao modelo do professor reflexivo, pois, ao focar o desenvolvimento real do professor, é preciso considerar a importância de trazer para os processos formativos as condições sociais constitutivas da educação escolar. Zeichner (2008, p. 542) destaca que um:

[...] aspecto do insucesso da formação docente reflexiva para promover o desenvolvimento real dos professores é a ênfase clara do foco interiorizado das reflexões dos professores sobre o seu próprio ensino e sobre os estudantes, desconsiderando-se as condições sociais da educação escolar que tanto influenciam o trabalho docente em sala de aula. Esse viés individualista faz com que seja menos provável que professores sejam capazes de confrontar e transformar os aspectos estruturais de seu trabalho que minam a possibilidade de atingirem seus objetivos educacionais. Não se discute o contexto do trabalho docente.

Para compreender as condições constitutivas das relações nos espaços escolares, é necessário que se avance para uma formação que caracterize o docente como pesquisador e não apenas como professor reflexivo.

Segundo Pesce e André (2012), a formação do professor pesquisador pode dar condições de o professor assumir a sua própria realidade escolar como um objeto de pesquisa, de reflexão e de análise, constituindo-se em um movimento contra-hegemônico ante o processo de desprofissionalização do professor e de instrumentalização da sua prática. Da mesma forma, pode ser um estímulo à implementação de novas modalidades de formação e de uma área teórico-metodológica imensa da pesquisa em educação, especialmente sobre a formação do professor e a prática pedagógica.

A formação do professor pesquisador também pode ser vista como uma forma de ajudar a melhorar o ensino, possibilitando que o docente exerça, com os alunos, um trabalho que vise à formulação de novos conhecimentos ou o questionamento tanto sobre a validade quanto sobre a pertinência dos já existentes. É essencial que o professor deixe de ser um técnico, reprodutor das práticas convencionais que são internalizadas pela força da tradição e passe a ser autor de sua ação educativa. Para Lüdke (2006), a prática da pesquisa dá mais recurso ao professor para questionar sua prática, levando-o a uma profissionalidade autônoma e responsável. Lüdke realça ser necessário que o futuro professor tenha acesso à formação e à prática da pesquisa. A formação inicial representa o lócus fundamental para que o profissional possa desenvolver uma postura investigativa. Ao formar-se (entender-se) professor pesquisador, seu pensamento e sua prática serão constitutivos desse saber.

Nas diretrizes propostas em 2015, há uma indicação de que a formação para a pesquisa deve ser contemplada nos projetos pedagógicos dos cursos de licenciatura, o que não era evidente nas diretrizes de 2002. Portanto, em 2016, os cursos voltaram a reformular seus projetos pedagógicos considerando a

[...] garantia de concepção de formação pautada tanto pelo desenvolvimento de sólida formação teórica e interdisciplinar em educação de crianças, adolescentes, jovens e adultos(as) e nas áreas específicas de conhecimento científico quanto pela unidade entre teoria e prática e pela centralidade do trabalho como princípio educativo na formação profissional, como também pelo entendimento de que a pesquisa se constitui em princípio cognitivo e formativo e, portanto, eixo nucleador dessa formação. (DOURADO, 2015, p. 301). 
Outro aspecto a ser observado na reformulação dos cursos é que a formação deve estar pautada em "um projeto formativo nas instituições de educação sob uma sólida base teórica e interdisciplinar que reflita a especificidade da formação docente, assegurando organicidade ao trabalho das diferentes unidades que concorrem para essa formação" (BRASIL, 2015, p. 4). Nessa direção, a universidade pesquisada já tem uma organização que propicie atividades interdisciplinares, possibilitando ao professor formador compreender que, para atuar na docência, é preciso ter domínio do conhecimento específico de sua área para então poder dialogar com outras áreas do conhecimento. Esse aspecto é destacado pela fala do Professor E:

Dominar os conceitos, dominar os fatos, os conteúdos que dão corpo a essa área disciplinar para poder aí fazer os diálogos com outras disciplinas. Eu acredito que essa seja a condição elementar. Eu dominar muito bem a minha área original de formação para poder fazer pontes, diálogos e apropriações de conceitos de outras áreas e elaborar problemas comuns de estudo com outras áreas de conhecimento.

Outro aspecto a ser considerado é "o reconhecimento das instituições de educação básica como espaços necessários à formação dos profissionais do magistério" (BRASIL, 2015, p. 4). Além das atividades desenvolvidas na escola, a exemplo do estágio curricular supervisionado, a experiência do professor formador na Educação Básica é fundamental para legitimar esses aspectos, como se pode observar nas palavras do Professor E: "Eu leciono no Ensino Básico, então sempre que possível, sempre que é pertinente, eu estou relacionando a disciplina com a realidade da sala de aula, com o Ensino Básico".

Os participantes da pesquisa deixaram evidente que as reformulações dos projetos pedagógicos dos cursos de licenciatura em que atuam proporcionaram o reconhecimento da Escola Básica como parceira na formação inicial docente, tanto pelas experiências deles mesmos na Educação Básica quanto do reconhecimento da importância de políticas como o PIBID.

\section{CONSIDERAÇões FinAIS}

As diretrizes propostas em 2002 já provocaram avanços na formação inicial oferecida pelas instituições de ensino superior em diversos aspectos, sobretudo relacionados à maior inserção da prática pedagógica nos currículos. Na universidade pesquisada, os colegiados discutiram e implementaram novos projetos pedagógicos com um perfil profissiográfico comum aos egressos dos cursos de licenciatura, contemplando as diretrizes por meio da implantação do Núcleo Pedagógico Integrador, possibilitando a integração entre diferentes áreas do conhecimento.

O objetivo da pesquisa foi compreender como os professores formadores perceberam os impactos das diretrizes curriculares para a formação inicial. Os participantes da pesquisa indicaram que as mudanças nos projetos pedagógicos proporcionam a formação de um profissional que saiba conviver com diferentes perspectivas técnico-científicas e diferentes conjuntos de valores, que compreende o diálogo entre os diferentes saberes e reconhece a 
escola como espaço de formação.

Os participantes também destacam a importância de políticas como o PIBID para a formação inicial, uma vez que, além de proporcionar a aproximação entre a universidade e a escola, o licenciando tem a oportunidade de desenvolver os saberes relacionados ao seu campo de trabalho. Além disso, de acordo com a análise das entrevistas, na escola o licenciando tem a oportunidade de vivenciar situações de ensino e aprendizagem, momento em que ele as relaciona com os conhecimentos adquiridos no curso de formação.

Por outro lado, nota-se que na fala dos professores formadores entrevistados há um silenciamento da pesquisa como princípio cognitivo e formativo, a qual deveria ser um dos eixos nucleadores da formação docente, tendo em vista que a pesquisa pode ser compreendida como um recurso indispensável ao trabalho do professor, tanto sobre sua área específica como sobre sua prática pedagógica, as quais, na maior parte das vezes, estão integradas. Com base nas discussões propostas para a reformulação dos cursos, fazem-se necessárias novas pesquisas a fim de compreender o movimento dialético que caracteriza esse fenômeno social.

Outro tema não abordado pelos participantes é a preocupação com a formação continuada para promover a profissionalização docente já na fase inicial de formação. As universidades devem cumprir seu papel no sentido de estabelecer relação entre ensino, pesquisa e extensão, ao fomentar a ampliação de grupos de pesquisa envolvendo professores e acadêmicos das licenciaturas, alunos e professores do stricto senso e docentes da Educação Básica. Tais grupos podem auxiliar na formação de um professor pesquisador e aproximar a universidade da Educação Básica.

Portanto, o perfil do docente tanto do(a)

[...] egresso(a) da formação inicial e continuada deverá possuir um repertório de informações e habilidades composto pela pluralidade de conhecimentos teóricos e práticos, resultado do projeto pedagógico e do percurso cuja consolidação virá do seu exercício profissional, fundamentado em princípios de interdisciplinaridade, contextualização, democratização,pertinênciaerelevânciasocial,éticaesensibilidadeafetivaeestética,demodo alhe[s]permitir:oconhecimentodainstituiçãoeducativa; apesquisa; atuaçãoprofissionalnoensino, nagestãode processos educativos e na organização e gestão de instituições de educação básica. (DOURADO, 2015,p. 307).

A proposta de educação deve ser um projeto social, político e ético que venha para consolidar uma nação soberana, justa, democrática e inclusiva e a fim de promover a emancipação dos indivíduos. Como afirma Severino (2006, p. 212):

A escola é o lugar institucional de um projeto educacional. Isso quer dizer que ela deve instaurar-se como espaço-tempo, como instância social que sirva de base mediadora e articuladora dos outros dois projetos que têm a ver com o agir humano: de um lado o projeto político da sociedade e, de outro, os projetos pessoais dos sujeitos envolvidos na educação.

Para solidificar esse projeto educacional, são propostas novas diretrizes para formação de profissionais de magistério da Educação Básica (BRASIL, 2015), pois a formação de professores está diretamente relacionada a um projeto educacional abrangente. Portanto, os docentes egressos devem estar preparados para assumir a escola em seu projeto educacional. Diante disso, novamente os projetos pedagógicos dos cursos de licenciatura passam por processos de reformulação. Na presente pesquisa os professores formadores já sinalizam em suas falas 
alguns temas emergentes, especialmente no sentido de formar um professor pesquisador e também de proporcionar a articulação entre pesquisa, ensino e extensão na universidade.

\section{REFERÊNCIAS}

ANDRÉ, M. E. D. A. Questões sobre os fins e sobre os métodos de pesquisa em educação. Revista Eletrônica de Educação, v. 1, n. 1, set. 2007. Disponível em: <http://www.reveduc.ufscar.br/index.php/ reveduc/article/viewFile/6/6>.

BRASIL. Conselho Nacional de Educação. Resolução n. ${ }^{0}$ 1, de 18 de fevereiro de 2002. Institui diretrizes curriculares nacionais para a formação de professores da educação básica, em nível superior, curso de licenciatura, de graduação plena. Disponível em: <http://portal.mec.gov.br/seesp/arquivos/pdf/res1_2.pdf>.

BRASIL. Conselho Nacional de Educação. Resolução n. ${ }^{\circ}$ 2, de $1 .^{\circ}$ de julho de 2015. Define as diretrizes curriculares nacionais para a formação inicial em nível superior (cursos de licenciatura, cursos de formação pedagógica para graduados e cursos de segunda licenciatura) e para a formação continuada. Diário Oficial da União, Brasília, seção 1, n. 124, p. 8-12, jul. 2015. Disponível em: <http://pesquisa.in.gov.br/imprensa/jsp/ visualiza/index.jsp?data $=02 / 07 / 2015 \&$ jornal $=1 \&$ pagina $=8 \&$ totalArquivos $=72>$.

CAPES. COORDENAÇÃO DE APERFEIÇOAMENTO DE PESSOAL DE NÍVEL SUPERIOR. Portaria Normativa n. ${ }^{0}$ 16, de 23 de dezembro de 2009. Programa Institucional de Bolsas de Iniciação Docência. 2009. Disponível em: <http://www.capes.gov.br/images/stories/download/bolsas/Portaria16_241209.pdf>.

CONTRERAS, J. A autonomia de professores. São Paulo: Cortez, 2002.

DOURADO, L. F. Diretrizes curriculares nacionais para a formação inicial e continuada dos profissionais do magistério da educação básica: concepções e desafios. Revista Educação e Sociedade, Campinas, v. 36, n. 131, p. 299-324, abr.jun., 2015. Disponível em: <http://www.scielo.br/pdf/es/v36n131/1678-4626-es-36131-00299.pdf>.

FAZENDA, I. Formação de professores: dimensão interdisciplinar. Revista Brasileira de Formação de Professores, v. 1, n. 1, p. 103-109, maio 2009.

FORMOSINHO, J. (Org.) Formação de professores - aprendizagem profissional e a acção docente. Porto: Porto, 2009.

GATTI, B. A. Formação de professores: condições e problemas atuais. Revista Brasileira de Formação de Professores, v. 1, n. 1, p. 90-102, 2009.

; ANDRÉ, M. E. D. A. A relevância dos métodos de pesquisa qualitativa em educação no Brasil. In: WELLER, W.; PFAFF, N. Metodologia da pesquisa qualitativa em educação: teoria e prática. Petrópolis: Vozes, 2010.

IMBERNÓN; F. Formação docente e profissional - formar-se para a mudança e a incerteza. São Paulo: Cortez, 2011.

LÜDKE, M. A complexa relação entre o professor e a pesquisa. In: ANDRÉ, M. E. D. A. (Org.). O papel da pesquisa na formação e na prática dos professores. 5. ed. Campinas: Papirus, 2006. p. 27-54.

; ANDRÉ, M. E. D. A. Pesquisa em educação: abordagens qualitativas. São Paulo: EPU, 1986.

MARCELO, C. Desenvolvimento profissional docente: passado e futuro. Sisifo, Revista de Ciência da Educação, n. 8, p. 7-22, jan./abr. 2009. Disponível em: <http://www.fep.porto.ucp.pt/sites/default/files/files/ 
FEP/SAME/docs/Carlosmarcelo_Desenv_Profissional.pdf $>$.

MAY, T. Pesquisa social: questões, métodos e processos. Tradução de Carlos Alberto Silveira Netto Soares. 3. ed. Porto Alegre: Artmed, 2004.

NÓVOA, A. (Org.). Os professores e a sua formação. Lisboa: Publicações Dom Quixote, 1992.

PÉREZ GÓMEZ, A. Formando professores como profissionais reflexivos. In: NÓVOA, A.(Org.). Os professores e sua formação. 2. ed. Lisboa: Publicações Dom Quixote, 1995.

PESCE, M. K.; ANDRÉ, M. E. D. A. Formação do professor pesquisador na perspectiva do professor formador. Formação Docente, Belo Horizonte, v. 4, n. 7, p. 39-50, jul./dez. 2012. Disponível em: <http:// formacaodocente.autenticaeditora.com.br/artigo/exibir/12/54/1>.

ROMANOWSKI, J.P.; MARTINS, P. L. O. A didática na formação pedagógica de professores nas novas propostas para a formação de professores. In: DALBEN, A. et al. (Orgs.). Convergências e tensões no campo da formação e do trabalho docente: didática, formação docente, trabalho docente. Belo Horizonte: Autêntica, 2010. (Didática e prática de ensino).

SEVERINO, A. J. Fundamentos ético-políticos da educação no Brasil de hoje. In: LIMA, J. C. F.; NEVES, L. M. W. (Orgs.). Fundamentos da educação escolar do Brasil contemporâneo. Rio de Janeiro: FIOCRUZ, 2006.

TARDIF, M. Saberes docentes e formação profissional. 13. ed. Petrópolis: Vozes, 2011.

; LESSARD, C. Trabalho docente: elementos para uma teoria da docência como profissão de interações humanas. Petrópolis: Vozes, 2005.

TRIVIÑOS, A. N. S. Introdução à pesquisa em ciências sociais: a pesquisa qualitativa em educação. São Paulo: Atlas, 1987.

ZEICHNER. K. M. Uma análise crítica sobre a "reflexão" como conceito estruturante na formação docente. Educação e Sociedade, Campinas, v. 29, n. 103, p. 535-554, maio/ago. 2008. Disponível em: <http://www. cedes.unicamp.br>.

Artigo recebido em: 25/03/2017

Aprovado em: 03/07/2017

Contato para correspondência:

Jane Mery Richter Voigt. E-mail: jane.mery@univille.br 